\title{
PREVALENCE AND CORRELATES OF ADULT ATTENTION DEFICIT DISORDER (ADHD) AMONG COLLEGE GOING YOUNG ADULT MALES WITH RISKY SEXUAL BEHAVIOUR
}

\author{
Shankar Kumar1, Kasthuri Pandiyan², Varun Huilgol ${ }^{3}$, Chandrashekar Hongally 4
}

${ }^{1}$ Lecturer, Department of Psychiatry, Bangalore Medical College and Research Institute (BMC and RI), Bangalore.

${ }^{2}$ Assistant Professor, Department of Psychiatry, Bangalore Medical College and Research Institute (BMC and RI), Bangalore.

$3 J u n i o r$ Resident, Bangalore Medical College and Research Institute (BMC and RI), Bangalore.

4 Professor and HOD, Department of Psychiatry, Bangalore Medical College and Research Institute (BMC and RI), Bangalore.

\section{ABSTRACT}

\section{BACKGROUND}

Symptoms of ADHD continue to be present in two-thirds of individuals in adulthood. Around $2 \%$ - $8 \%$ of college going adolescents have ADHD symptoms. Sexual experimentation usually begins in adolescence with multiple psychosocial factors contributing to its initiation. ADHD is known to be associated with risky sexual behaviour.

This study was undertaken to find the prevalence of ADHD and risky sexual behaviour and its association with impulsivity, positive and negative affect in college going young adult males.

\section{MATERIALS AND METHODS}

It was a cross-sectional study done in 3 colleges in Bangalore city; 305 self-report questionnaires were distributed after stratified random sampling, of which 270 responded. The questionnaires included a sociodemographic questionnaire, Adult ADHD SelfReport Rating Scale (ASRS), Wender Utah Rating Scale (WURS). For those who scored above the cut-off on both ASRS and WURS, Positive and Negative Affect Rating Scale (PANAS) and Barratt's impulsivity scale-11 (BIS-11) were administered to measure impulsivity and positive and negative affect. Analysis was done using SPSS V-19.

\section{RESULTS}

The prevalence of ADHD in our sample of college going male students was $14.81 \%(n=40)$. Those with ADHD had lower scores in preceding exam $(p=0.0006)$ and had higher prevalence of substance use than those without ADHD ( $p=0.0001)$. Overall, the prevalence of any risky sexual behaviour was $42.5 \%(n=17)$ in those with ADHD as compared to $13.91 \%(n=32)$ in those without ADHD. Those with ADHD had higher prevalence of multiple sex partners, lower rates of condom use and sex with strangers. Those with ADHD had higher negative affect $(\mathrm{p}=0.03)$, but not higher positive affect or impulsivity than those without ADHD.

\section{CONCLUSION}

There was a high prevalence of ADHD in college going young adult males who had higher risky sexual behaviour than those without ADHD. Negative affect predicted risky sexual behaviour in this sample.

\section{KEYWORDS}

Attention Deficit Disorder with Hyperactivity, Sexual Behaviour, Impulsive Behaviour, Risk-Taking.

HOW TO CITE THIS ARTICLE: Kumar S, Pandiyan K, Huilgol V, et al. Prevalence and correlates of adult attention deficit disorder (ADHD) among college going young adult males with risky sexual behaviour. J. Evolution Med. Dent. Sci. 2017;6(17):1367-1370, DOI: $10.14260 / J e m d s / 2017 / 297$

\section{BACKGROUND}

Attention Deficit Hyperactivity Disorder [ADHD] is a neurobehavioural disorder characterised by either significant difficulties of inattention or hyperactivity and impulsivity or a combination of the two; $15 \%-20 \%$ of children with ADHD maintain the full diagnosis and as many as $30 \%-60 \%$ of these will maintain the full diagnosis or some residual symptoms as adults.(1) The prevalence rate of ADHD in the adult population as per National Comorbidity Survey is $4.4 \%{ }^{(2)}$ It is estimated that around $2 \%-8 \%$ of college going students have ADHD.(3)

Financial or Other, Competing Interest: None.

Submission 20-01-2017, Peer Review 12-02-2017,

Acceptance 20-02-2017, Published 27-02-2017.

Corresponding Author:

Dr. Shankar Kumar

Lecturer, Department of Psychiatry,

Victoria Hospital,

Bangalore Medical College and Research Institute (BMC and RI),

Fort, Bangalore- 560002

E-mail: shankarkjs@gmail.com

DOI: $10.14260 /$ jemds $/ 2017 / 297$

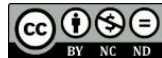

However, research on this is largely derived from the United States. Accumulating research suggests that college students with ADHD experience less academic success and have greater psychological and emotional difficulties than other students.(4) Such students with ADHD also use alcohol and drugs at higher rates, probably to cope up with demands as a result of poor executive functioning seen in ADHD.

Sexual experimentation usually begins in adolescence. Casual sex among youth is influenced by multiple factors such as individual psychological factors, social factors and relational variables. In this study, we chose to study ADHD as a factor influencing risky sexual behaviour in this age group.

ADHD can be a developmental precursor of early onset risky behaviours. Those with childhood ADHD were more likely than those without ADHD to report risky sexual behaviours such as casual sex, infrequent condom use and multiple sex partners.(5) Adults with ADHD who present with risky sexual behaviours may also have a higher prevalence of sexually transmitted infections including HIV.(6) Studies have reported that presence of comorbid conditions such as Conduct Disorder, Anti-Social Personality traits, Depression, Poor parenting, High family conflict could contribute to the 
association of ADHD and risky sexual behaviour along a cumulative risk model.(7)

There is a significant paucity of Indian data on the study of ADHD in contributing to risky sexual behaviour among college going adolescents. In this background, we undertook this study with the following aims and objectives-

- To assess the prevalence of ADHD in college going young adult males.

- To assess prevalence and patterns of risky sexual behaviour in college going young adult males.

- To study the relationship between impulsivity and negative affect on high risk sexual behaviour.

\section{MATERIALS AND METHODS}

\section{Type of Study}

Cross-sectional study.

\section{Site of Study}

3 colleges catering to General Arts and Science, Engineering, Medical Degrees in Bangalore city.

\section{Study Sample}

A total of 305 questionnaires were distributed among males in the above colleges after informed consent and permission from college authorities, of which 270 responded. Stratified random sampling was used for the study. Only males were chosen as ADHD is more common in male population. Among those who scored above the cut-off for ADHD as defined subsequently, the next set of questionnaires to measure positive and negative affect and parental bonding were administered.

\section{Age Group}

Those between 16 to 25 years of age were chosen.

\section{Inclusion Criteria}

1. Those who gave informed consent (English speaking).

2. Young adult males aged between $16-25 \mathrm{yrs}$.

\section{Exclusion Criteria}

1. Those who were on previous psychiatric treatment.

2. Those with substance use (Exclusion of nicotine).

Risky Sexual behaviour in the study was defined as presence of one or more of the following - Multiple sex partners, failure to use condom, using substances before sex, sex with CSW's and anal sex.

\section{Instruments used for the Study}

1. Sociodemographic details including age, years of education was collected. Details regarding risky sexual behaviour was collected using items from Youth Risk Behaviour Survey.

2. Adult ADHD self-report scale [ASRS V 1.1] was used to screen for Adult ADHD. The Symptom Checklist is an instrument consisting of the eighteen DSM-IV-Text Revision (TR) criteria for ADHD in adulthood. Six of the eighteen questions were found to be the most predictive of symptoms consistent with ADHD. A cut-off of 15 was used to diagnose ADHD. (8)
3. Wender Utah Rating Scale (WURS) was used for retrospective childhood diagnosis of ADHD. A cut-off of 46 as suggested was taken.(9)

4. Positive and Negative Affect Scale (PANAS) - It is a 20 item scale, which measures positive and negative affect dimensions over a period of one week. A mean of 33 for positive affect and 17 for negative affect was taken significant as per author's suggestions.(10)

5. Barratt's Impulsivity Scale (BIS) - 11 item - it is an abbreviated version of the full BIS which measures impulsivity.(11)

All instruments are self-rated. The questionnaires were administered by the investigator in a place, which ensured privacy and confidentiality.

All questionnaires were collected on the same day after the subjects scored them. They were also given an option to ask the investigator for any help regarding answering or queries regarding the same.

Data was compiled and Pearson/Spearman correlation, ttest to find out significance between variables, multiple logistic regression using risky sex as dependent variable and ASRS, negative affect and impulsivity as predictor variables were calculated.

\section{RESULTS}

\begin{tabular}{|c|c|c|c|}
\hline & $\begin{array}{c}\text { With ADHD } \\
(\mathbf{n}=\mathbf{4 0})\end{array}$ & $\begin{array}{c}\text { Without ADHD } \\
(\mathbf{n = 2 3 0 )}\end{array}$ & P value \\
\hline Age (years) & $17.25(3.16)$ & $19.32(4.45)$ & $0.005^{*}$ \\
\hline $\begin{array}{c}\text { Years of } \\
\text { Education }\end{array}$ & $10.45(2.34)$ & $11.56(2.02)$ & $0.001^{*}$ \\
\hline $\begin{array}{c}\text { Score Last } \\
\text { Exam (\%) }\end{array}$ & $59.43(12.32)$ & $64.77(8.33)$ & $0.0006^{*}$ \\
\hline $\begin{array}{c}\text { Presence of } \\
\text { Substance } \\
\text { Use }\end{array}$ & 22 & 34 & $0.0001^{*}$ \\
\hline \multicolumn{4}{|c|}{ Table 1. Sociodemographic Data } \\
\hline
\end{tabular}

Note - $\mathrm{t}$-test was used for the first 3 variables and Fisher's exact test for the last.

\begin{tabular}{|c|c|c|c|}
\hline & $\begin{array}{c}\text { With } \\
\text { ADHD } \\
\text { (n= 17) }\end{array}$ & $\begin{array}{c}\text { Without } \\
\text { ADHD } \\
\text { (n= 32) }\end{array}$ & P value \\
\hline Sex with Strangers & 8 & 12 & $0.003^{*}$ \\
\hline $\begin{array}{c}\text { Irregular use of } \\
\text { Condoms }\end{array}$ & 7 & 10 & $0.005^{*}$ \\
\hline Anal Sex & 3 & 5 & 0.09 \\
\hline Multiple Sex Partners & 10 & 12 & $0.0003^{*}$ \\
\hline $\begin{array}{c}\text { Age of Initiation of } \\
\text { Sexual Activity (years) }\end{array}$ & $15.4(2.56)$ & $17.43(3.22)$ & 0.02 \\
\hline Table 2. Patterns of Risky Sexual Behaviour among \\
those With and Without ADHD \\
\hline
\end{tabular}

Note - Fisher's exact test was used to analyse differences.

\begin{tabular}{|c|c|c|c|c|}
\hline & ADHD & No ADHD & T value & P value \\
\hline Positive Affect & $\begin{array}{c}26.90 \\
(10.65)\end{array}$ & $\begin{array}{c}29.68 \\
(10.26)\end{array}$ & 0.82 & 0.41 \\
\hline Negative Affect & $\begin{array}{c}25.72 \\
(10.91)\end{array}$ & $\begin{array}{c}19.79 \\
(7.67)\end{array}$ & 2.19 & $0.03^{*}$ \\
\hline Impulsivity & $\begin{array}{c}19.63 \\
(2.18)\end{array}$ & $\begin{array}{c}18.79 \\
(3.35)\end{array}$ & 0.84 & 0.42 \\
\hline
\end{tabular}

Table 3. Comparison of Scores between those With and Without ADHD using T-Test

Note - Negative affect was higher among those with ADHD 


\begin{tabular}{|c|c|c|}
\hline & R value & P value \\
\hline ADHD vs Positive Affect & 0.22 & 0.7 \\
\hline ADHD vs Negative Affect & 0.23 & $0.04^{*}$ \\
\hline ADHD vs Impulsivity & 0.09 & 0.9 \\
\hline \multicolumn{2}{|c|}{ Table 4. Correlation between ADHD } \\
Scores and other Parameters \\
\hline
\end{tabular}

Note $-r=$ Pearson's correlation coefficient

\begin{tabular}{|c|c|c|c|}
\hline & Odds Ratio & $\mathbf{9 5 \%}$ CI & P value \\
\hline ADHD & 0.98 & $0.8-1.10$ & 0.78 \\
\hline Negative Affect & 1.40 & $1.30-1.45$ & $0.02^{*}$ \\
\hline Impulsivity & 0.89 & $0.76-1.04$ & 0.16 \\
\hline \multicolumn{4}{|c|}{ X2 $=7.20, \mathrm{df}=3, \mathrm{p}=0.05$} \\
\hline Table 5. Multiple Logistic Regression to Calculate \\
Odds of having Risky Sexual Behaviour \\
\hline
\end{tabular}
affect.

Note- Risky sexual behaviour was predicted by negative

\section{DISCUSSION}

\section{Sociodemographic Data}

The prevalence of ADHD in our sample of college going male students was $14.81 \%$, which was slightly higher compared to data from the West.(3) This could be because our sample consisted of males only and ADHD is known to have a higher prevalence in males.

Those without ADHD had higher years of education than those with ADHD. Also, those with ADHD had lower marks in the preceding exam than those without ADHD. It is known that ADHD contributes to academic underachievement in school and college-going children and adolescents.(12)

More numbers of those with ADHD had substance use than those without ADHD. ADHD is known to be associated with early onset substance use, especially alcohol use which tends to be more severe than those without ADHD.(13)

\section{Risky Sexual Behaviours}

Overall, the prevalence of any risky sexual behaviour was $42.5 \%(\mathrm{n}=17$ ) in those with ADHD as compared to $13.91 \%$ ( $\mathrm{n}=32$ ) in those without ADHD. Those with ADHD had earlier onset of sexual activity than those without ADHD. Those with ADHD also had higher prevalence of risky sexual behaviours assessed in the study which included sex with strangers, irregular condom use and multiple partners. This is in concordance with existing literature, which states that ADHD is associated with early sexual debut and multiple risky sexual behaviours, (5) which also may be associated with a higher prevalence of sexually transmitted infections.(6)

\section{Factors Associated with Risky Sexual Behaviour}

Those with ADHD had higher negative affect scores as measured by PANAS than those without ADHD.(14) Risky sexual behaviour was predicted by negative affect scores, but not ADHD, impulsivity or positive affect in logistic regression. Those with ADHD generally have higher positive affect scores. In our study, we could not replicate the same. This could be because studies have reported higher positive affect in those without comorbidities. Our sample had high prevalence of substance use and mood disorders were not assessed. Higher negative affect in ADHD could contribute to substance use and risky sexual behaviours, the direction of association needs to be established in larger studies in future.

\section{Limitations}

1. Small sample size.

2. Psychopathology such as substance use, mood disorders and psychosocial factors such as poor parenting, parental psychopathology, temperament which contributes to risky sexual behaviour were not assessed systematically.

\section{CONCLUSION AND FUTURE DIRECTIONS}

There is a high prevalence of ADHD among college-going adolescent males. These students with ADHD have a high prevalence of risky sexual behaviours. Negative affect in ADHD contributes to risky sexual behaviours. There is a need for large scale research in this area to elucidate the role of ADHD and associated comorbidities in contributing to risky sexual behaviour among college-going adolescents to plan for effective interventions.

\section{REFERENCES}

[1] Weiss G, Hechtman L. Hyperactive children grown up. ADHD in children, adolescents and adults. Guildford, New York 1993.

[2] Kessler RC, Adler L, Barkley R, et al. The prevalence and correlates of adult ADHD in the United States: results from the national comorbidity survey replication. Am J Psychiatry 2006;163(4):716-23.

[3] Dupaul GJ, Weyandt LL, O'Dell SM, et al. College students with ADHD: current status and future directions. J Atten Disord 2009;13(3):234-50.

[4] Heiligenstein E, Guenther G, Levy A, et al. Psychological and academic functioning in college students with attention deficit hyperactivity disorder. J Am Coll Health 1999;47(4):181-5.

[5] Barkley RA, Fischer M, Smallish L, et al. Young adult outcome of hyperactive children: adaptive functioning in major life activities. J Am Acad Child Adolesc Psychiatry 2006;45(2):192-202.

[6] Kumar S, Shekar A, Das G, et al. Prevalence of adult attention deficit hyperactivity disorder and its correlates among recently diagnosed young adult males with HIV. J AIDS Clin Res 2014;5:314.

[7] Price MN, Hyde JS. When two isn't better than one: predictors of early sexual activity in adolescence using a cumulative risk model. Journal of Youth and Adolescence 2009;38(8):1059-71.

[8] Kessler RC, Adler L, Ames M, et al. The world health organization adult ADHD self-report scale (ASRS): a short screening scale for use in the general population. Psychol Med 2005;35(2):245-56.

[9] Ward MF, Wender PH, Reimherr FW. The wender utah rating scale: an aid in the retrospective diagnosis of childhood attention deficit hyperactivity disorder. Am J Psychiatry 1993;150(6):885-90.

[10] Crawford JR, Henry JD. The positive and negative affect schedule (PANAS): construct validity, measurement properties and normative data in a large non-clinical sample. British Journal of Clinical Psychology 2004;43(3):245-65.

[11] Patton JH, Stanford MS, Barratt ES. Factor structure of the barratt impulsiveness scale. Journal of Clinical Psychology 1995;51(6):768-74. 
[12] DeShazo BT, Lyman RD, Klinger LG. Academic underachievement and attention-deficit/hyperactivity disorder: the negative impact of symptom severity on school performance. Journal of School Psychology 2002;40(3):259-83.

[13] Kumar S, Pandiyan K, Hongally C. Prevalence and correlates of adult attention deficit hyperactivity disorder (adhd) in early onset alcohol dependence in a tertiary care hospital. Journal of Research in Psychiatry and Behavioral Sciences 2015;1(1):1-5.
[14] Okado I, Mueller CW, Nakamura BJ. Positive and negative affect in clinic-referred youth with ADHD. Journal of Attention Disorders 2016;20(1):53-62. 